\title{
Memorandum on design-oriented information systems research
}

\author{
Hubert Österle ${ }^{1}$, \\ Jörg Becker², \\ Ulrich Frank ${ }^{3}$, \\ Thomas Hess ${ }^{4}$, \\ Dimitris Karagiannis ${ }^{5}$, \\ Helmut Krcmar ${ }^{6}$, \\ Peter Loos? \\ Peter Mertens ${ }^{8}$, \\ Andreas Oberweis $^{9}$ \\ and Elmar J. Sinz ${ }^{10}$
}

\footnotetext{
${ }^{1}$ University of St. Gallen, St. Gallen, Switzerland; ${ }^{2}$ ERCIS, University of Münster, Germany;

${ }^{3}$ University of Duisburg-Essen, Essen, Germany; ${ }^{4}$ Ludwig-Maximilian-University, Munich, Germany; ${ }^{5}$ University of Vienna, Vienna, Austria; ${ }^{6}$ Technical University Munich, Munich, Germany; ${ }^{7}$ Saarland University, Saarbruecken, Germany; ${ }^{8}$ University of Erlangen-Nuremberg, Nuremberg, Germany; ${ }^{9}$ Karlsruhe Institute of Technology, Karlsruhe, Germany; ${ }^{10}$ University of Bamberg, Bamberg, Germany.
}

Correspondence: Hubert Österle, Institute of Information Management, University of St. Gallen, Mueller-Friedberg-Strasse 8, St. Gallen 9000, Switzerland.

Tel.: + 417122424 17;

Fax: + 417122427 77;

E-mail: hubert.oesterle@unisg.ch

(This memorandum was originally published in German in the Zeitschrift für betriebswirtschaftliche Forschung (zfbf), Volume 62, pp. 662-672 and is translated and reprinted here with the kind permission of Fachverlag der Verlagsgruppe Handelsblatt GmbH. The authors would like to acknowledge the generous assistance of EIIS Senior Associate Editor Nicholas Romano who helped with the translation from the German.)

Received: 28 September 2010

Revised: 21 October 2010

Accepted: 23 October 2010

\begin{abstract}
Information Systems Research ("Wirtschaftsinformatik") basically follows two research approaches: the behavioristic approach and the design-oriented approach. In this memorandum, 10 authors propose principles of design-oriented information systems research. Moreover, the memorandum is supported by 111 full professors from the German-speaking scientific community, who with their signature advocate the principles specified therein.

European Journal of Information Systems advance online publication, 7 December 2010; doi:10.1057/ejis.2010.55
\end{abstract}

Keywords: information systems research; business systems engineering; research methodology; design science research; behavioral research publication

\section{Preamble}

Is information systems (IS) research supposed to be beneficial for society and business? Until recently, this question was answered with a clear 'Yes' by the European IS research community, particularly by the German speaking countries and Scandinavia, who were proud to graduate students with fundamental knowledge concerning the design and implementation of innovative business solutions that both business and public administration demanded. Also, these researchers could cite numerous examples where scientific results produced in their field had successfully been transferred to various areas in society and business. These examples are founded in the close collaboration between scientists and business, as well as in the unity of research and teaching. Thereby, both scholars and students are aware of their domain's reality.

In the Anglo-Saxon world, the corresponding research area to the German term 'Wirtschaftsinformatik' (recently translated as 'business and information systems engineering') is IS research. Rooted in the business school culture, it is based on a behaviorist approach. Rather than aiming at the design of innovative IS, it focuses more on observing IS characteristics and user behavior. In doing so, this research has been able to produce valuable finding in a number of areas; for example, the preferences of internet users or the use of online services. However, leading exponents of the discipline have complained for years that research in the field has lacked relevance for the practitioners' community, which could be surmised from the fact that very few Ph.D.s from the IS discipline have ended up working in business.

Reinforced by the Bologna Process, cross-national evaluation of the performance and capabilities of universities and researchers has been established in the member states of the European Union in recent years (e.g. the German excellence initiative). The easiest evaluation form that is intersubjectively verifiable is to count publications in international scientific journals (i.e. journals published in English, as English is the 
lingua franca in the sciences). The journals most relevant are based in the Anglo-Saxon scientific community, predominantly following behaviorism as the guiding research paradigm.

In the effort to have their work published in these journals, researchers, and young researchers in particular, have no other choice but to comply with the journals' evaluation criteria for paper submissions. Basically, these criteria say that publications providing statistical evidence of empirically identified characteristics of existing IS are favored over publications presenting innovative solutions that are considered highly beneficial for business. The consequences of this development can be seen in many areas. Today, habilitation and tenure procedures, applications for research grants, and rankings increasingly tend to require those criteria. One can no longer deny that European IS research is in danger of shifting from a design-oriented discipline into a descriptive one.

If we seek the cause for this quite questionable trend (both from a societal and a business perspective), the discipline itself needs to be put under scrutiny. IS researchers in Europe have often preferred publishing books to publishing papers in journals, they have largely neglected publishing in English, which is required to be visible on a global level, and they have shown little commitment to the international scientific community. The most prominent objective of European IS research has basically been to produce practically beneficial, business relevant results. Adoption of these results by business (i.e. economic payoff) has often been considered more important in terms of providing evidence of the correctness of results than transparent, well-documented scientific development of results following generally accepted criteria (i.e. scientific rigor). Inevitably, in some cases, this has led to the publication of results that fall short of rigorous scientific standards.

European IS research has an excellent opportunity to build upon its strengths in terms of design orientation and at the same time demonstrate its scientific rigor through the use of generally accepted methods and techniques for acquiring knowledge. Recently, a newly emerging branch of Anglo-Saxon IS research known as design science strives for the same objective as European IS research does in order to meet the demand for more practical relevance of scientific results.

The authors of the memorandum aim at the following objectives:

- To provide rules for scientific rigor and improved guidance for researchers.

- To provide criteria for journal and conference reviewers work.

- To provide criteria for selection of young researchers and tenure procedures.

- To provide criteria for evaluation of researchers and research organizations.

- To position design-oriented IS research in the international research community.
While the memorandum's initiators and signers advocate the idea of design-oriented IS research, they also explicitly welcome behavioral research and the pluralism of methods in the discipline. They strive for rigorous, yet relevant research and they follow this view when selecting reviewers for editorial boards and specifying review criteria, when evaluating researchers and teachers in tenure tracks and tenure procedures, when creating incentive systems (e.g. rankings), and when deciding on research funding. They call for support of their concern from all stakeholder groups, particularly from the economic and the political system.

\section{Stakeholder groups}

Design-oriented IS research targets individuals and organizations that provide resources for the research and, in return, expect favorable results for themselves. Important stakeholders of design-oriented IS research are economic players (e.g. companies, managers, employees), public administration, the political system, all kinds of groups in society (e.g. tax payers, students, road users, patients, bank customers), and representatives from other sciences (e.g. business sciences). All these groups demand that design-oriented IS research produce artifacts that should yield a certain benefit.

\section{Research object}

Design-oriented IS research deals with IS both for organizations and individuals in society and economy. IS are sociotechnical in nature and comprised of three object types, namely people (i.e. human task bearers), information and communications technology (i.e. technical task bearers), and organizational concepts (i.e. functions, structures, processes), and the interrelationships between them.

The body of knowledge of design-oriented IS research is constituted by the scientific literature produced by the discipline and - to a much larger extent - by the experiences and knowledge accumulated in business concerning IS, software products, organizational concepts, methods, and tools.

\section{Research objectives}

Design-oriented IS research aims to develop and provide instructions for action (i.e. normative, practically applicable means-ends conclusions) that allow the design and operation of IS and innovative concepts within IS (instances). Thus, for each specific IS that is developed design-oriented IS research builds upon a 'to-be' conception and then searches for the means to construct the system according to this model while taking into account given restrictions and limitations.

In contrast, behaviorism-based IS research analyzes existing IS as phenomena (showing factual characteristics) in order to be able to identify causal relations.

\section{Result types}

Design-oriented IS research aims at the development of artifacts, namely constructs (e.g. concepts, terminologies, 
and languages), models, methods, and instantiations (i.e. concrete solutions implemented as prototypes or production systems).

Concrete manifestations of such artifacts can be axioms, guidelines, frameworks, norms, patents, software (with open source code), business models, enterprise start-ups, and much more.

\section{Research process}

Ideally, design-oriented IS research follows an iterative process comprising four basic phases:

\section{Analysis}

Research may be initiated by any stakeholder including the scientific and the practitioner community or by both communities together. The business problem is identified and described, and research objectives, questions, and gaps are specified. The state of the art of problem-solving approaches known in business and science is outlined and analyzed. A research plan is put forward for the development and improvement of artifacts required.

External factors that affect the problem are also identified and selected, taking into account contingency.

Design-oriented IS research deals with various kinds of research questions and takes advantage of a broad range of research methods and linguistic mechanisms (e.g. Unified Modeling Language). Research planning ensures appropriate configuration of research methods and language means best suited to the specific project.

2. Design

Artifacts should be created through generally accepted methods, be justified as much as possible and be contrasted with solutions already known in science and business.

\section{Evaluation}

Scientific rigor demands validation of artifacts produced against the objectives specified, applying the methods stated in the research plan. The review process prior to scientific publications is part of the evaluation.

4. Diffusion

To achieve the best possible diffusion of results among the target groups, design-oriented IS research mainly uses the following instruments: scientific papers, practitioner papers, conference papers, oral presentations, dissertation theses, habilitation theses, technical books, textbooks, lectures, seminars, on-the-job training, funding applications, instantiations in companies and public administration, enterprise start-ups, and spin-offs.

\section{Research methods}

Design-oriented IS research uses research methods taken from business, social, computer, and engineering sciences.

Frequently used methods for exploration in the analysis phase are surveys, case studies, expert interviews, and IS analysis (e.g. database analysis).
Typical methods for artifact design are demonstration or prototype construction, modeling with CASE tools, reference modeling, and method engineering.

Artifact evaluation is done through laboratory experiments, pilot applications (i.e. instantiation of prototypes), simulation procedures, expert reviews, and field experiments (i.e. instantiations in a number of user organizations).

\section{Research principles}

Scientific research in general needs to be characterized by abstraction, originality, justification, and publication in order to distinguish itself from the way solutions are developed in the practitioners' community (e.g. in user organizations) or by commercial providers (e.g. software vendors, consulting companies).

Specifically, design-oriented IS research must comply with four basic principles:

- Abstraction: Each artifact must be applicable to a class of problems.

- Originality: Each artifact must substantially contribute to the advancement of the body of knowledge.

- Justification: Each artifact must be justified in a comprehensible manner and must allow for its validation.

- Benefit: Each artifact must yield benefit - either immediately or in the future - for the respective stakeholder groups.

Another important principle applied in design-oriented IS research is deductive reasoning. The ideal case is to formally deduct (i.e. mathematically) or to use semiformal (i.e. conceptual) instruments; however in most cases design-oriented IS research takes advantage of natural-language (i.e. argumentative) deduction, taking into account existing theories and models. Designoriented IS research thus contributes substantially to the structuring and integration of the body of knowledge. But design-oriented IS research uses also inductive reasoning (e.g. when inferring from single case studies).

Socio-technical systems typically involve a huge number of factors and variables, therefore design-oriented IS research usually does not result in deterministic solutions. Only in rare cases can an artifact produced be (formally) verified. Rather, an artifact is either accepted or rejected by experts reviewing how it has been justified or judging the implementation outcome.

Design-oriented IS research is not a non-judgmental scientific discipline, rather it is normative, in a sense that the construction of artifacts is guided by the desire to yield a specific benefit and to satisfy certain objectives.

Design-oriented IS research espouses academic freedom in science and teaching. Researchers are free to decide on research objectives and research methods, as well as publication of research results and stakeholder satisfaction, as long as they adhere to the above mentioned principles. 


\section{The undersigned}

The undersigned declare to fully agree with this memorandum and make efforts to effectively promote the viewpoints and principles stated therein.
(For space reasons we do not repeat the list of 111 signatories here. The full list of signatories is published in the original German version in Zeitschrift für betriebswirtschaftliche Forschung (zfbf), Volume 62, pp. 662-672).

\section{About the authors}

Hubert Österle holds a doctorate in business management from the University Erlangen-Nuremberg (Germany) and a habilitation from the University of Dortmund (Germany). After working with IBM, he was appointed chair of the Institute of Information Management at the University of St. Gallen (Switzerland). He is editor-in-chief of 'Electronic Markets. The International Journal on Networked Business'.

Jörg Becker holds the Chair for Information Systems (IS) and Information Management at the Westfälische Wilhelms-Universität Münster. He is Managing Director of the European Research Center for IS ERCIS, a network of 20 mostly European Research Centers. He serves as Prorector (Vice President) of the Westfälische WilhelmsUniversität Münster.

Ulrich Frank holds the chair of IS and Enterprise Modeling at the University of Duisburg-Essen. He is editor-in-chief of the journal 'Enterprise Modeling and Information Systems Architectures' and member of the editorial boards of the journals 'Information Systems and EBusiness Management' and 'Business \& Information Systems Engineering'.

Thomas Hess studied Information Systems at the Technichal University of Darmstadt and earned a doctoral degree from the University of St. Gallen. After working for Bertelsmann he joined the University of Goettingen as a post-doc. Since 2001, he has been professor at the University of Munich (LMU) and director of the Institute for IS and New Media at LMU.

Dimitris Karagiannis has been full professor for Business Informatics at the University of Vienna since 1993 and is head of the Department Business and Knowledge Engineering. His main research focus is on Metamodeling and Knowledge Engineering. Recently, he established the Open Model Initiative in Austria based on ADOxx $\mathbb{R}$ platform (www.openmodel.at).

Helmut Krcmar holds the chair for IS, faculty of informatics, Technical University Munich (TUM) and serves as dean of the faculty of informatics. He is also on the faculty of TUM Business School. He received a Ph.D. in business administration (University of Saarbrücken) and has worked as Post Doctoral Fellow at the IBM Los Angeles Scientific Center and as Assistant Professor of Information Systems (New York University).

Peter Loos is director of the Institute for Information Systems (IWi) at the German Research Institute for Artificial Intelligence (DFKI) and head of the chair for Business Administration and IS at Saarland University. His research activities include business process management, information modeling, enterprise systems, software development as well as implementation of IS.

Peter Mertens is professor emeritus for business applications of IT (Wirtschaftsinformatik), University of ErlangenNuremberg. Prior to his career as a university professor he was CEO of a larger Swiss software company. He was editor-in-chief of 'WIRTSCHAFTSINFORMATIK' for 11 years. Moreover he was/is a member of the editorial boards of several journals, inter alia 'Decision Support Systems'.

Andreas Oberweis is professor for Applied Informatics at the Karlsruhe Institute of Technology (KIT). Since 2004, he has also been director at the Research Center for Information Technology (FZI) Karlsruhe. He received a doctoral degree from University of Mannheim in 1990 and a habilitation degree in Applied Informatics from Universitaet Karlsruhe in 1995. From 1995 to 2003, he was professor for IS Development at Goethe-Universitaet Frankfurt/Main.

Elmar J. Sinz studied mechanical engineering and business management. He holds a doctorate and a habilitation from the University of Regensburg (Germany). After deputizing for a professorship at the University of Marburg he was appointed chair of IS and Systems Engineering at the University of Bamberg (Germany). Elmar J. Sinz is co-editor of 'WIRTSCHAFTSINFORMATIK'. 